\title{
Rationale and design of the 500-patient, 3-year, and prospective Vigilant Observatlon of GlladeL WAfer ImplaNT registry
}

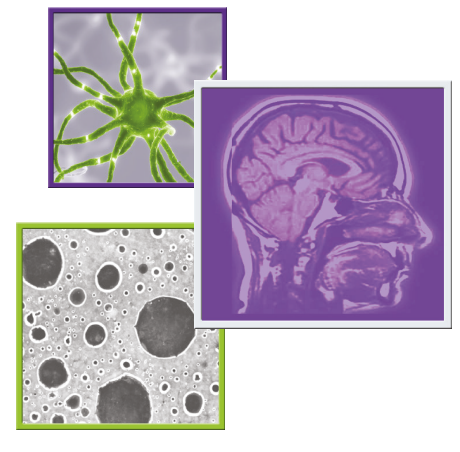

Kevin O Lillehei*,1, Steven N Kalkanis², Linda M Liau³, Dellann Elliott Mydland4 ${ }^{3}$, Jeffrey Olson $^{5}$, Nina A Paleologos ${ }^{6}$, Timothy Ryken ${ }^{7}$, Tania Johnson ${ }^{8}$ \& Evan Scullin ${ }^{8}$

${ }^{1}$ Department of Neurosurgery, University of Colorado School of Medicine, Denver, CO, 80045, USA

${ }^{2}$ Department of Neurosurgery, Henry Ford Hospital, Detroit, MI, 48202, USA

${ }^{3}$ Department of Neurosurgery, David Geffen School of Medicine, UCLA, Los Angeles, 90095, CA, USA

${ }^{4}$ EndBrainCancer Initiative, Redmond, WA, 98052, USA

${ }^{5}$ Department of Neurosurgery, Emory University, Atlanta, GA, 30322, USA

${ }^{6}$ Department of Neurology, Advocate Healthcare, Chicago, IL, 60515, USA

${ }^{7}$ Department of Neurosurgery, Dartmouth-Hitchcock Medical Center, Lebanon, NH, 03756, USA

${ }^{8}$ Arbor Pharmaceuticals, LLC, Atlanta, GA, 30328, USA

*Author for correspondence: Tel.: +1 303724 2305; kevin.lillehei@ucdenver.edu

\section{Summary points}

- Implantation of biodegradable wafers impregnated with carmustine (BCNU) is one of the few chemotherapeutic modalities to have been evaluated in Phase III trials for treatment of newly diagnosed high-grade glioma and recurrent glioblastoma.

- The prospective Vigilant Observatlon of GlladeL WAfer ImplaNT (VIGILANT) registry (NCT02684838) will evaluate BCNU wafers for treatment of CNS malignancies in contemporary practice.

- The VIGILANT registry will critically examine which patients might most benefit from the implantation of BCNU wafers in this new era of molecular tumor analysis.

- Enrolling 500 patients at over 30 sites, the VIGILANT registry will be one of the largest prospective observational studies ever conducted to track outcomes and practice patterns for treatment of CNS malignancies.

- Subgroup analyses will include tumor type, molecular marker status, and treatment combinations.

Implantationof biodegradable wafers impregnated with carmustine (BCNU) is one of the few chemotherapeutic modalities that have been evaluated in Phase III trials and approved by the US FDA for treatment of newly diagnosed high-grade glioma and recurrent glioblastoma. Enrolling up to 500 patients for 3-year follow-up at over 30 sites, the prospective Vigilant Observatlon of GlladeL WAfer ImplaNT (VIGILANT) registry (NCT02684838) will evaluate BCNU wafers for treatment of CNS malignancies in contemporary practice and in the new era of molecular tumor analysis. Subgroup analyses will include tumor type, molecular marker status, and treatment combinations. Interim analyses from the VIGILANT registry will be reported until complete results are available in 2024.

First draft submitted: 11 October 2017; Accepted for publication: 13 November 2017; Published online: 5 December 2017

Keywords: BCNU wafers $\bullet$ chemotherapy $\bullet$ glioblastoma $\bullet$ high-grade glioma $\bullet$ multimodality $\bullet$ patterns of care $\bullet$ study protocol

BCNU wafers (Gliadel ${ }^{\circledR}$, Arbor Pharmaceuticals LLC, GA, USA) are biodegradable copolymers (prolifeprospan 20) impregnated with the alkylating agent carmustine (BCNU [1,3-bis (2-chloroethyl)-1-nitrosourea]) (Figure 1) [1,2]. The wafers were originally developed by Brem and colleagues at Johns Hopkins University School of Medicine to avoid the toxicity associated with systemic administration of BCNU [3]. At that time, intravenous BCNU was a standard treatment for high-grade glioma (HGG), with a modest survival benefit [4]. The concept of locally introducing an antineoplastic therapy into CNS tumors, thereby bypassing the blood-brain barrier, spurred evaluation of several new approaches, including intranasal and convection-enhanced delivery [5]. 


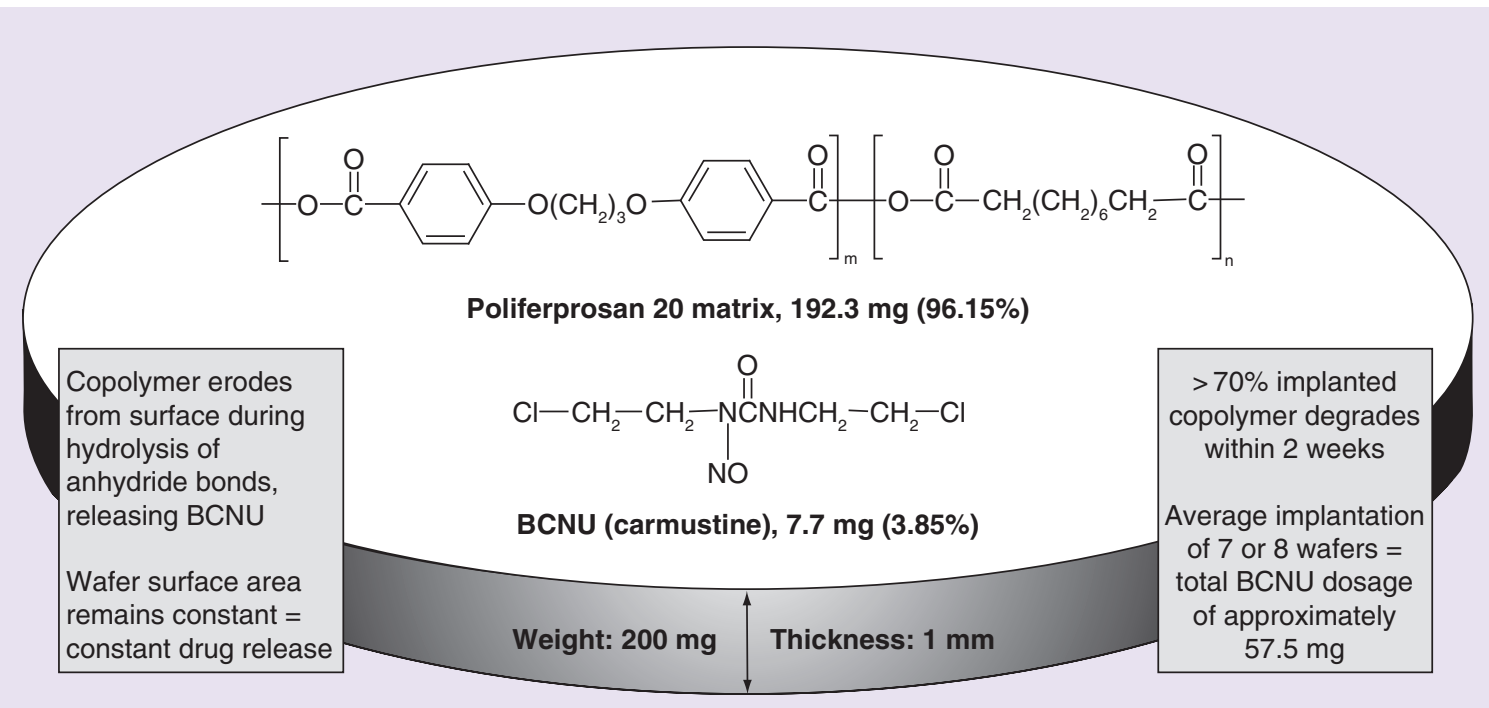

Diameter: $14.5 \mathrm{~mm}$

Figure 1. Schematic drawing of biodegradable wafers impregnated with carmustine.

The BCNU wafer releases BCNU at a constant rate over a period of a week. Transport into the tissue adjacent to the implant occurs primarily by diffusion, which is augmented immediately postresection by convective transport with interstitial flow resulting from vasogenic edema. More than $70 \%$ of the copolymer degrades by 3 weeks [2].

BCNU: 1,3-bis(2-chloroethyl)-1-nitrosourea.

In a Phase III, multicenter, and placebo-controlled trial in 222 patients with recurrent HGG, Brem et al. demonstrated improved 6-month mortality comparing BCNU wafers with placebo wafers ( 40 vs $53 \% ; \mathrm{p}=0.06$ ), with a median overall survival (OS) increase of 8 weeks ( 31 vs 23 weeks; $p=0.06$ ) [6]. Two-thirds of these patients had recurrent glioblastoma $(\mathrm{GBM})$, and $\mathrm{BCNU}$ wafers were associated with significantly reduced 6-month mortality in this patient subset ( 44 vs 64\%; $\mathrm{p}=0.02$ ). In 1997, the US FDA approved BCNU wafers for treatment of recurrent GBM.

Subsequently, two Phase III, multicenter, and placebo-controlled trials evaluated BCNU wafer implantation in patients with newly diagnosed HGG. In a study of 32 patients, Valtonen et al. demonstrated a significant median survival benefit of 18.2 weeks for BCNU wafers followed by radiotherapy (RT) compared with placebo wafers followed by RT ( 58.1 vs 39.9 weeks; $\mathrm{p}=0.012$ ) [7]. Then, in a study of 240 patients, Westphal et al. demonstrated a significant median survival benefit of 2.3 months for BCNU wafers followed by RT compared with placebo wafers followed by RT (13.9 vs 11.6 months; $\log$-rank $\mathrm{p}=0.03$, stratified by country) [8,9]. In this Phase III trial, the incidence of postoperative cerebral spinal fluid leaks (16.0 vs $12.0 \%)$ and intracranial hypertension (9.0 vs $2.0 \%$ ) was higher in patients receiving BCNU wafers than in patients receiving placebo wafers. In 2003, the FDA approved BCNU wafers for the treatment of newly diagnosed HGG (WHO grade III and grade IV glioma). The Phase III trials of BCNU wafers are summarized in Table 1.

The development and the FDA approval of BCNU wafers represented the first major advance in the treatment of HGG since 1978, when RT was adopted as the standard adjuvant treatment of HGG [10]. To date, the FDA has only approved one additional chemotherapeutic agent for the treatment of newly diagnosed HGG, temozolomide (TMZ) (Temodar, Merck \& Co., NJ, USA) in 2005 [11], as well as one additional chemotherapeutic agent for the treatment of recurrent GBM in 2009, bevacizumab (Avastin, Genentech, CA, USA) [12].

In 2005 the European Organization for Research and Treatment of Cancer (EORTC) Brain Tumor and Radiotherapy Groups and the National Cancer Institute of Canada (NCIC) published the results of a Phase III multicenter, double-blind, and placebo-controlled trial treating 573 patients with RT alone versus RT with concurrent daily oral TMZ followed by six cycles of adjuvant TMZ for five consecutive days every 28 days (a regimen abbreviated here as RT/TMZ) [13,14]. The EORTC/NCIC study demonstrated a significant median survival benefit of 2.5 months with RT/TMZ compared with treatment with RT alone (14.6 [95\% CI: 13.2-16.8] vs 12.1 months 


\begin{tabular}{|c|c|c|c|c|c|}
\hline Study (year) & $\begin{array}{l}\text { Study type, } \\
\text { indication }\end{array}$ & Study description & Efficacy results & Safety results & Ref. \\
\hline Brem et al. (1995) & $\begin{array}{l}\text { Phase III, } \\
\text { recurrent HGG }\end{array}$ & $\begin{array}{l}222 \text { patients treated with surgery } \\
\text { and either BCNU wafers or } \\
\text { placebo wafers }\end{array}$ & $\begin{array}{l}\text { Median postimplant survival } \\
(p=0.006): 31 \text { weeks for BCNU } \\
\text { wafers versus } 23 \text { weeks for placebo } \\
\text { wafers }\end{array}$ & $\begin{array}{l}\text { Similar seizure rates for each group, } \\
\text { with nonsignificant increase in } \\
\text { intracranial infection in BCNU group } \\
\text { ( } 3.6 \text { vs } 0.89 \% \text { ) }\end{array}$ & [6] \\
\hline $\begin{array}{l}\text { Valtonen et al. } \\
\text { (1997) }\end{array}$ & $\begin{array}{l}\text { Phase III, ND } \\
\text { HGG }\end{array}$ & $\begin{array}{l}32 \text { patients with newly } \\
\text { diagnosed HGG treated with } \\
\text { surgery and either BCNU wafers } \\
\text { or placebo wafers }\end{array}$ & $\begin{array}{l}\text { Median OS }(p=0.012): 58.1 \text { weeks } \\
\text { for BCNU wafers versus } 39.9 \text { weeks } \\
\text { for placebo wafers }\end{array}$ & $\begin{array}{l}\text { Infection noted in treatment group, } \\
\text { frequency not reported }\end{array}$ & [7] \\
\hline $\begin{array}{l}\text { Westphal et al. } \\
(2003 / 2006)\end{array}$ & $\begin{array}{l}\text { Phase III, ND } \\
\text { HGG }\end{array}$ & $\begin{array}{l}240 \text { patients with newly } \\
\text { diagnosed HGG treated with } \\
\text { surgery and either BCNU wafers } \\
\text { or placebo wafers }\end{array}$ & $\begin{array}{l}\text { Median intent-to-treat OS }(p=0.05) \text { : } \\
13.9 \text { months for } B C N U \text { wafers versus } \\
11.6 \text { months for placebo wafers }\end{array}$ & $\begin{array}{l}\text { CSF leaks ( } 16.0 \text { vs } 12.0 \%) \text { and } \\
\text { intracranial hypertension ( } 9.0 \text { vs } \\
2.0 \% \text { ) were more common in the } \\
\text { BCNU group than in the placebo } \\
\text { group }\end{array}$ & {$[8,9]$} \\
\hline
\end{tabular}

BCNU: 1,3-bis(2-chloroethyl)-1-nitrosourea; CSF: cerebospinal fluid; HGG: High-grade glioma; ND HGG: Newly diagnosed high-grade glioma; OS: Overall survival.

[95\% CI: $11.2-13.0]$ ). At 2 years, OS in the RT/TMZ treatment arm increased from 10.9 to $27.2 \%$. In 2005 , the FDA approved TMZ for use in newly diagnosed GBM in accordance with the dose schedule established by the EORTC/NCIC study. Since then, the RT/TMZ regimen has been 'standard of care' for histologically confirmed newly diagnosed GBM following surgical biopsy or resection.

There are thus few FDA-approved chemotherapeutic agents available for patients with either newly diagnosed HGG or recurrent GBM. In recent large Phase III trials in newly diagnosed HGG, several other chemotherapeutic agents have failed to improve survival beyond what was achieved in the EORTC/NCIC study [15-17]. At the same time, a number of prospective single-arm or retrospective studies have suggested that the combination of BCNU wafers plus RT/TMZ may improve survival by several months beyond that provided by either therapy alone, without a significant increase in toxicity [18]. In addition, two recent meta-analyses have affirmed this survival benefit for $\mathrm{BCNU}$ wafers $[19,20]$. BCNU wafers are used worldwide, with regulatory approval most recently granted in Japan in 2012 and in Mexico in 2015.

There is thus a need for a large-scale evaluation of the performance of BCNU wafers in the contemporary treatment of newly diagnosed and recurrent HGG, critically examining, in this new era of molecular tumor grading, which patients might most benefit from implantation of BCNU wafers. A means for this evaluation is the Vigilant ObservatIon of GlIadeL WAfer ImplaNT (VIGILANT) registry (NCT02684838), a prospective, observational study of up to 500 patients prescribed BCNU wafers as part of the treatment of either newly diagnosed or recurrent CNS malignancies of all kinds. This article describes the rationale and design of the VIGILANT registry, with the intent of encouraging active participation and stimulating anticipation of results.

\section{Background \& rationale}

Emergence of molecular biomarker profiling

At the time of the development of BCNU wafers in the mid 1990s and early 2000s, testing was not available for predictive and prognostic molecular biomarkers. In the current era of molecular medicine, it is appropriate to revisit the performance of BCNU wafer implantation for treatment of HGG [20]. It is possible that improvement of survival with BCNU wafer implantation may be limited to particular subgroups of patients with specific molecular markers. The addition of BCNU wafers to the RT/TMZ regimen could then be potentially tailored to those patients with a favorable molecular profile.

After significant restructuring in 2016, the WHO classification of CNS tumors now employs molecular parameters in addition to histology in order to define tumor entities, changing the structure of CNS tumor diagnoses for the molecular age. [21] The updated guidelines merge astrocytic gliomas, oligodendrogliomas, and mixed oligoastrocytic gliomas, all of which were formerly considered separate entities, into the single group 'diffuse astrocytic and oligodendroglial tumors'. GBMs (WHO grade IV) are the most malignant within the spectrum of diffuse astrocytomas, accounting for $60 \%$ of all astrocytic tumors. Tumors categorized as diffuse gliomas frequently have an isocitrate dehydrogenase $(I D H)$ mutation, a hallmark genetic alteration that is now seen as a significant factor for the stratification of gliomas. In the new WHO classification, GBMs are grouped as wildtype (about $90 \%$ of cases) 
and mutant (about $10 \%$ of cases) [21]. Mutations in $I D H-1$ and $I D H-2$ are found to be associated with favorable prognosis and prolonged OS [22].

Another important molecular marker is the gene encoding the $\mathrm{O}^{6}$-methylguanine-DNA methyltransferase (MGMT) at 10q26, which has the potential to counteract the efficacy of separate chemotherapy with alkylating agents like TMZ and BCNU. MGMT is a suicide DNA repair enzyme that protects cells against damage from ionizing and alkylating agents. GBM cells that express decreased levels of MGMT, with downregulation caused by aberrant methylation of the gene's promoter, respond better to these treatments, for they lack the ability to repair the damage that is introduced. The association between $M G M T$ promoter methylation and response to alkylating agents is well known [23], and contemporary HGG trials of alkylating agents commonly stratify patients according to $M G M T$ promoter methylation status [24].

Codeletion of both the short arm of chromosome 1 (1p) and the long arm of chromosome 19 (19q) is the molecular genetic signature of oligodendrogliomas, which represent approximately $15 \%$ of diffuse gliomas in adults [25]. The $1 \mathrm{p} / 19 \mathrm{q}$ codeletion is associated with $I D H$ mutations and is a strong independent prognostic biomarker for response to alkylating chemotherapy and improved survival [26].

Yet another recognized molecular marker is the epidermal growth factor receptor ( $E G F R)$ gene. GBMs have been found to upregulate several growth factors and their receptors. The EGFR gene is the most frequently amplified and overexpressed gene in about $60 \%$ of GBMs. EGFR amplification has been linked to increased proliferation, resistance to chemotherapy, and consequently shorter survival times [27].

\section{BCNU wafers combined with other therapies}

The Phase III trial of BCNU wafers and the Phase III trial of RT/TMZ for treatment of newly diagnosed GBM each demonstrated an increase in median OS when compared with RT alone. For BCNU wafers in the 240-patient HGG Westphal et al. Phase III trial, median OS increased from 11.6 to 13.9 months; for RT/TMZ in the 573patient EORTC/NCIC trial, median OS increased from 12.1 to 14.6 months in GBM patients. Since these trials were reported, interest has grown for investigating whether additional improvements to survival might be realized by sequential combination of the antiproliferative mechanisms of BCNU and TMZ. Because RT and concurrent TMZ do not usually begin until 3-6 weeks after resection, implanted BCNU wafers may provide treatment during the interim period between the resection and the start of RT/TMZ without significantly adding to or exacerbating the adverse effects of RT/TMZ.

A Phase III trial of RT/TMZ with and without BCNU wafers has not been conducted, and it is unlikely that one will be conducted. However, a number of prospective single-arm and retrospective studies have reported combination data for treatment of newly diagnosed HGG (Table 2). In a systematic review of such studies, Ashby et al. identified 11 articles published between 2008 and 2015 that met inclusion criteria [28-38]. These 11 articles report outcomes for 411 patients who received BCNU wafers plus standard RT/TMZ. Among these 11 studies, patients were similar in age, gender, and performance status; approximately $85 \%$ had newly diagnosed GBM. For the ten trials that reported median OS, the weighted mean was 18.2 months $(\mathrm{n}=379$ patients; range 12.7-21.3 months) - an improvement by 3-4 months compared with the previously reported median OS for BCNU wafers (13.9 months) [8] or for TMZ (14.6 months) [13] when either therapy was used alone with RT in a Phase III trial.

The 11 studies evaluated by Ashby et al. had substantial limitations: only three were prospective, several had small enrollments, only two undertook MGMT testing, and none assessed other biomarkers. Consequently, the relatively consistent increased survival benefit for combination therapy across these studies might reflect improved resection techniques and better neuro-oncologic care. On the other hand, the combined antiproliferative effects of the two separate and sequentially administered chemotherapies might have an additive effect in improving survival, as occurs for combination therapies used for other type of cancers.

In the systematic review, Ashby et al. found that nine of the 11 trials reported grade 3 and 4 adverse events in accordance with the Common Terminology Criteria for Adverse Events [39]. For 372 patients in these nine trials, a total of 147 grade 3 and 4 adverse events were reported. Myelosuppression (10.22\%), neurologic deficit (7.8\%), healing abnormalities (4.3\%), and seizures (3.0\%) were the most commonly reported grade 3 and 4 adverse events. These adverse events seemed to reflect the separate and independent adverse event profiles of BCNU wafers and RT/TMZ rather than any synergistically enhanced toxicity. For example, because only trace amounts of BCNU are found in the systemic circulation after release from the polymeric wafers, the common grade 3 and 4 adverse event, myelosuppression, was most likely due to the systemic toxicity of RT and/or TMZ. 


\begin{tabular}{|c|c|c|c|c|c|c|c|}
\hline Study (year) & Study phase & Treatment arms & $\begin{array}{l}\text { \# ND HGG (\# } \\
\text { GBM) }\end{array}$ & $\begin{array}{l}\text { Median OS } \\
(\mathrm{mo})\end{array}$ & $\begin{array}{l}\text { Median PFS } \\
\text { (mo) }\end{array}$ & Conclusion/comments/adverse events & Ref. \\
\hline $\begin{array}{l}\text { Aoki et al. } \\
(2014)\end{array}$ & Phase I/II & $\begin{array}{l}\text { Resection + BCNU } \\
\text { wafer + RT/TMZ }\end{array}$ & $16(9)$ & 20.2 & NA & $\begin{array}{l}\text { Adverse events for ND HGG patients }(n=16) \text { and } \\
\text { recurrent GBM patients }(n=8) \text { were merged; } \\
\text { there were } 15 \text { grade } 3 \text { or grade } 4 \text { adverse events }\end{array}$ & [28] \\
\hline $\begin{array}{l}\text { Bock et al. } \\
(2010)\end{array}$ & Retrospective & $\begin{array}{l}\text { Resection + BCNU } \\
\text { wafer + RT } / \mathrm{TMZ}\end{array}$ & $44(44)$ & 12.7 & 7 & $\begin{array}{l}19 \text { patients ( } 43 \%) \text { experienced } 46 \text { grade } 3 \text { or } \\
\text { grade } 4 \text { adverse events }\end{array}$ & [29] \\
\hline $\begin{array}{l}\text { Burri et al. } \\
\text { (2015) }\end{array}$ & Phase II & $\begin{array}{l}\text { Resection + BCNU } \\
\text { wafer + early TMZ } \\
\text { (day 4) + RT/TMZ }\end{array}$ & $46(43)$ & 18 & 8.5 & $\begin{array}{l}\text { There were } 39 \text { grade } 3 \text { or grade } 4 \text { adverse events, } \\
\text { with nine patients who received } 200 \mathrm{mg} / \mathrm{m}^{2} \text { doses } \\
\text { of } \mathrm{TMZ} \text { experiencing one or more episodes of } \\
\text { grade } 3 \text { or } 4 \text { thrombocytopenia }\end{array}$ & [30] \\
\hline $\begin{array}{l}\text { Duntze et al. } \\
\text { (2012) }\end{array}$ & $\begin{array}{l}\text { Prospective } \\
\text { observational }\end{array}$ & $\begin{array}{l}\text { Resection + BCNU } \\
\text { wafer + RT/TMZ }\end{array}$ & $92(74)$ & 18.8 & 10.5 & $\begin{array}{l}\text { There were } 29 \text { grade } 3 \text { or grade } 4 \text { adverse events } \\
\text { among } 92 \text { patients, the most common being } \\
\text { neurological deficits }(n=12)\end{array}$ & [31] \\
\hline $\begin{array}{l}\text { McGirt et al. } \\
(2009)\end{array}$ & Retrospective & $\begin{array}{l}(1) \\
\text { Resection + BCNU } \\
\text { wafer + RT/TMZ } \\
(2) \\
\text { Resection + BCNU } \\
\text { wafer + RT } \\
\text { (3) } \\
\text { Resection/biopsy + }\end{array}$ & $\begin{array}{l}33(33) \\
78(78) \\
45(45)\end{array}$ & $\begin{array}{l}20.7 * \\
12.4 \\
14.7\end{array}$ & NA & $\begin{array}{l}\text { BCNU wafer + RT/TMZ regimen was not associated } \\
\text { with an increase in perioperative morbidity in } \\
\text { comparison with BCNU wafer + RT alone; } \\
\text { incorporation of TMZ w/ or W/o BCNU wafer had } \\
\text { better OS compared with BCNU wafer + RT; grade } \\
3 \text { and grade } 4 \text { adverse events were not reported }\end{array}$ & [32] \\
\hline $\begin{array}{l}\text { Menei et al. } \\
(2010)\end{array}$ & Retrospective & $\begin{array}{l}\text { (1) } \\
\text { Resection + BCNU } \\
\text { wafer + RT/TMZ } \\
(2) \\
\text { Resection + BCNU } \\
\text { wafer + other } \\
\text { regimens }\end{array}$ & $83(72)$ & $\begin{array}{l}17 \\
\text { (all patients } \\
\text { receiving } \\
\text { BCNU } \\
\text { wafers) }\end{array}$ & NA & $\begin{array}{l}\text { There were four cases of seizure and nine cases of } \\
\text { intracranial hypertension; grade } 3 \text { and grade } 4 \\
\text { adverse events were not reported }\end{array}$ & [33] \\
\hline $\begin{array}{l}\text { Miglierini et al. } \\
\text { (2012) }\end{array}$ & Retrospective & $\begin{array}{l}\text { Resection + BCNU } \\
\text { wafer + RT/TMZ }\end{array}$ & $24(22)$ & 19.2 & 12.3 & $\begin{array}{l}3 \text { cases of grade } 3 \text { thrombocytopenia; ten patients } \\
\text { stopped TMZ early due to toxicity or early } \\
\text { progression }\end{array}$ & [34] \\
\hline $\begin{array}{l}\text { Noel et al. } \\
(2012)\end{array}$ & Retrospective & $\begin{array}{l}(1) \\
\text { Resection + BCNU } \\
\text { wafer + RT/TMZ } \\
(2) \\
\text { Resection/biopsy + }\end{array}$ & $\begin{array}{l}28(20) \\
37(16)\end{array}$ & $\begin{array}{l}20.6 \\
20.8\end{array}$ & $\begin{array}{l}12.9 \\
14\end{array}$ & $\begin{array}{l}\text { There were no differences in outcome between } \\
\text { groups; there were four cases of grade } 3 \\
\text { thrombocytopenia in patients receiving } \\
\text { combination therapy }\end{array}$ & [35] \\
\hline Pan et al. (2008) & Retrospective & $\begin{array}{l}\text { Resection + BCNU } \\
\text { wafer + RT/TMZ }\end{array}$ & $21(21)$ & 17 & 8.5 & $\begin{array}{l}\text { There was one case of grade } 3 \text { cerebritis and one } \\
\text { case of altered mental status }\end{array}$ & [36] \\
\hline $\begin{array}{l}\text { Pavlov et al. } \\
\text { (2015) }\end{array}$ & Retrospective & $\begin{array}{l}\text { Resection + BCNU } \\
\text { wafer + RT/TMZ }\end{array}$ & $83(83)$ & 19.5 & 8.5 & $\begin{array}{l}\text { There were six cases of grade } 3 \text { and } 4 \\
\text { complications: two cases of intracranial } \\
\text { hypertension; three cases or neurological deficits; } \\
\text { and one case of myelosuppression }\end{array}$ & [37] \\
\hline $\begin{array}{l}\text { Salvati et al. } \\
\text { (2011) }\end{array}$ & Retrospective & $\begin{array}{l}\text { Resection + BCNU } \\
\text { wafer + RT } / \mathrm{TMZ}\end{array}$ & 32 (NA) & NA & NA & There were no grade 3 or 4 complications & [38] \\
\hline \multicolumn{8}{|c|}{$\begin{array}{l}{ }^{*}=\mathrm{p}<0.05 \\
\text { BCNU: 1,3-bis(2-chloroethyl)-1- nitrosourea; HGG: High-grade glioma; MGMT: O(6)-methylguanine-DNA methyltransferase; ND HGG: Newly diagnosed high-grade glioma; OS: Overall } \\
\text { survival; PFS: Progression-free survival; RT: Radiation therapy; TMZ: Temozolomide. }\end{array}$} \\
\hline
\end{tabular}

Recently, tumor-treating fields have been approved by the FDA for treatment of both newly diagnosed HGG and recurrent GBM [40]. These fields are low-intensity $(200 \mathrm{kHz})$ alternating electric fields that have been demonstrated to block cell division and interfere with organelle assembly. For newly diagnosed HGG, tumor-treating fields are administered with standard maintenance TMZ. To date, no data have been published about the combination of BCNU wafers with tumor-treating fields.

\section{BCNU wafers for treatment of recurrent HGG}

HGG recurs in virtually all patients after initial treatment. Due in part to the molecular heterogeneity and constant evolution of HGG, it is not possible to therapeutically target a consistently present and reliable final common pathway. The cellular and molecular heterogeneity is not unique to HGG among tumor types, but it is particularly pronounced for HGG tumors and may account for resistance to the therapies now available [41-43]. 
Currently, the standard of care for recurrent HGG remains undefined [44]. The American Association of Neurological Surgeons level 2 guidelines recommend that patients with recurrent HGG who have had previous surgical resection be considered for repeat surgery, taking into account performance status, tumor location and tumor size [45]. However, only an estimated $20-30 \%$ of patients with recurrent HGG qualify for a second resection and would possibly be eligible for implantation of BCNU wafers [44].

Few studies have evaluated the use of BCNU wafers for treatment of recurrent GBM since the 1995 Phase III randomized controlled study by Brem et al. [6]. Recently, Klein et al. retrospectively analyzed outcomes in three different group of patients with recurrent GBM [46]. Median survival after progression was 9.2 months in elderly patients (>65 years) receiving BCNU wafers, 7.6 months in elderly patients not receiving BCNU wafers $(\mathrm{p}=0.34)$, and 9.2 months in younger patients receiving BCNU wafers $(\mathrm{p}=0.35)$. There were no significant differences in adverse events between elderly and younger patients receiving BCNU wafers, although there was a tendency for elderly patients to experience more seizures (five of 24 patients vs two of 39 patients).

\section{Contemporary patterns of care}

Beginning 20 years ago, the Glioma Outcomes Project initiated a prospective observational registry in order to track practice patterns and outcomes among patients with malignant glioma. Between 1997 and 2000, 134 clinicians enrolled 788 patients at 52 clinical sites. In a series of publications, the Glioma Outcomes Project provided benchmark data to enable comparison of individual practice patterns and outcomes, flagging patterns that conflicted with current guidelines and those that suggested the need for further research [47-52].

One of the surprising findings of the Glioma Outcomes Project was demonstration that the level of clinical trial participation for patients with newly diagnosed or recurrent HGG was only 15.1\% [51,52]. Many contemporary clinical trials exclude patients who have received BCNU wafers rather than using that treatment as a stratification factor [53]. As a consequence, because the potential for clinical trial enrollment is rightfully considered important, patients who might benefit from local therapy with BCNU wafers but would not otherwise qualify for a clinical trial are not even counseled that the treatment is available. It is possible that imaging characteristics of BCNU wafers after implantation may be thought to increase the difficulty of interpreting radiographic progression in trials of new therapies. But the typical pattern of changes associated with BCNU wafer - implantation contrast enhancements and fluid-attenuated inversion recovery signal - has been well documented to peak 1 or 2 months after implantation [54,55].

Like the Glioma Outcomes Project, the VIGILANT registry will capture practice patterns, but now at a time of significant transformation in the classification and treatment of malignant gliomas. The evolution of intraoperative imaging, functional brain mapping, and photodynamic detection technology to distinguish tumor from brain has significantly improved the ability of neurosurgeons to undertake safer and more aggressive tumor resection. Understanding of tumor biology has improved significantly, tumor classification has been clarified, and application of genomic advances allows more precise selection of optimal therapy for individual patients. In particular, the initial assessment, management, and follow-up of patients with HGG now more frequently takes place in a multidisciplinary team setting that facilitates organized delivery of care, adherence to guidelines, and access to clinical trials. The VIGILANT registry will also track quality of life, a distinct outcome that can appreciably affect progression-free survival and OS. Patients with HGG are especially prone to quality-of-life challenges, ranging from fatigue and depression to seizures and focal neurologic deficits [56].

\section{Design of the VIGILANT registry \\ Design}

With a projected enrollment of 500 patients and a follow-up period of 3 years, the VIGILANT registry will examine the contemporary performance of $\mathrm{BCNU}$ wafers in the current era of molecular markers, gaining insights into what combination of factors can contribute to improving patient survival and quality of life. A schematic of the VIGILANT registry is provided in Figure 2.

At each participating site in the USA, the study will be reviewed and approved by the institutional review board/independent ethics committee. Data for each patient will be collected by means of an electronic case report form and data capture system.

Management of the VIGILANT registry is overseen by the sponsor of the registry, Arbor Pharmaceuticals. Members of the VIGILANT Registry Steering Committee are responsible for the prioritization of registry objectives, as well as for monitoring and reviewing the conduct of the registry, participation in data review, and oversight 


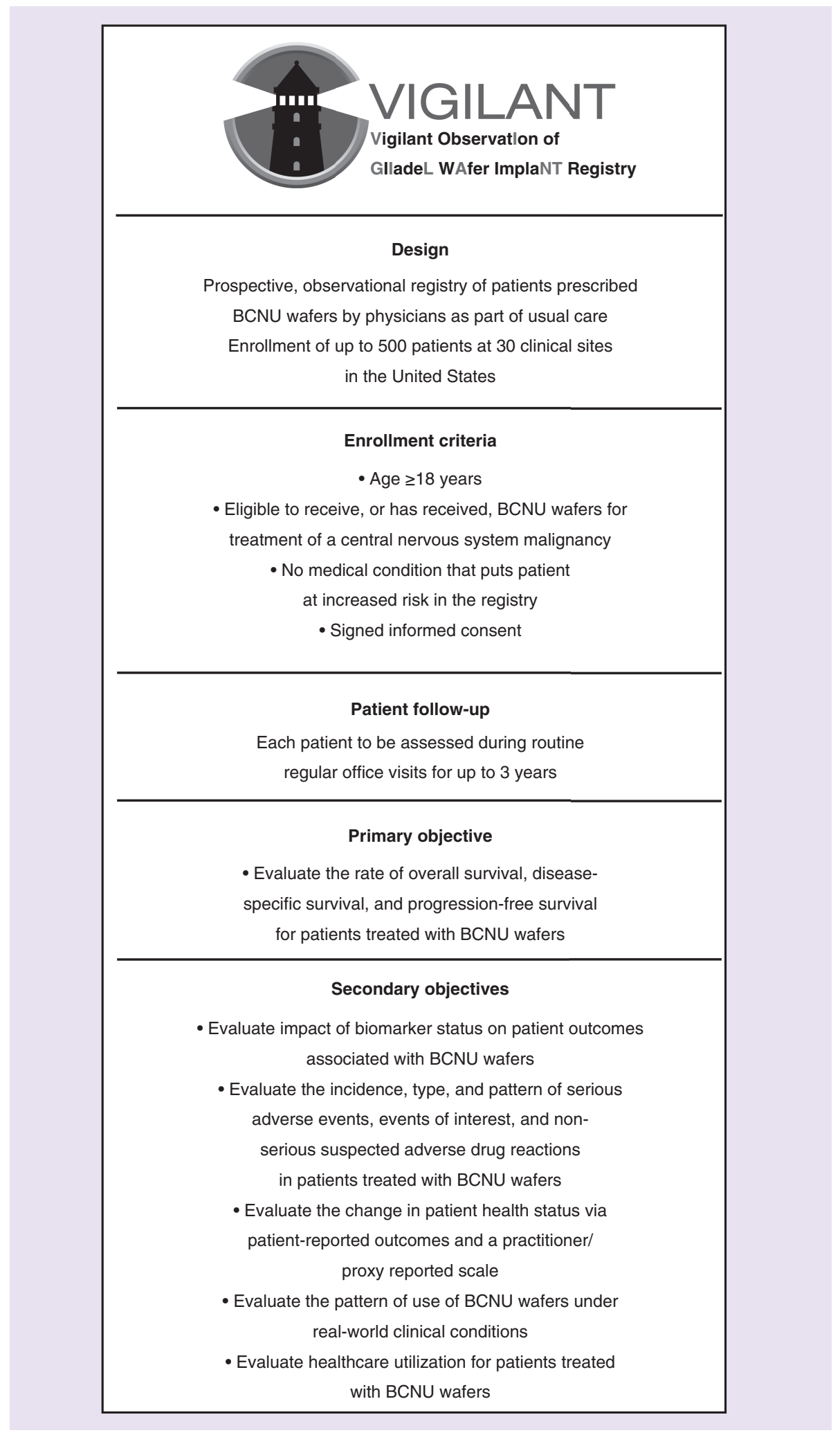

Figure 2. The Vigilant Observatlon of GlladeL WAfer ImplaNT registry trial schematic. BCNU: 1,3-bis(2-chloroethyl)-1-nitrosourea. 
of registry management and quality assurance practices. Under the guidance of the steering committee, periodic interim analyses of the VIGILANT registry will be performed and reported.

\section{Eligibility criteria}

The VIGILANT registry will enroll patients who have undergone BCNU wafer implantation as part of the usual care for the treatment of CNS tumors, including newly diagnosed and recurrent HGG. Because in current medical practice BCNU wafers are used in patients with various CNS tumor types, the VIGILANT registry is not limited to observation of patients with HGG. As an observational study, the VIGILANT registry does not alter patient/physician relationships and does not influence physician drug prescription or therapeutic management. Patients receive usual care from treating physicians.

Enrollment criteria for the VIGILANT registry are uncomplicated. Patients must be at least 18 years of age and have no medical conditions that, at investigator discretion, put them at increased risk by participation in the VIGILANT registry. This registry allows for patients to be simultaneously enrolled in a clinical trial provided that the trial does not exclude patients treated with BCNU wafers. Every patient must execute a medical record release form and sign informed consent to participate in the registry within 14 days after surgery for treatment of CNS tumors.

\section{Planned enrollment \& study length}

The sample size of approximately 500 patients for the VIGILANT registry was based on an assessment of feasibility rather than statistical factors. Each enrolled patient will remain in the registry for up to 3 years, and the registry itself will continue for up to 8 years.

\section{End points \& analyses}

The primary end points of the VIGILANT registry are overall, disease-specific, and progression-free survival rates for patients treated with BCNU wafers. Secondary end points include: the effect of biomarker status on patient outcomes; the incidence, types, and patterns of adverse events; changes in patient health status as assessed by the physician-completed Karnofsky Performance Status (KPS) scale [57]; changes in quality-of-life status as assessed by the patient-completed (FACT-Br) questionnaire; the patterns of use associated with BCNU wafers in real-world conditions; and healthcare utilization data based on length of hospitalization. Adverse events and serious adverse events will be recorded and assessed by the investigators for relatedness to the use of BCNU wafers. The quality of that relationship will be scored on the scale of definitely related, probably related, possibly related, unlikely related, and not related. All serious adverse events must be reported within $24 \mathrm{~h}$. The actions taken regarding each adverse event and related outcomes will also be recorded.

Collection of follow-up information will be performed during routine medical visits. There are no registryspecific visits required. At each office visit, the patient's follow-up imaging will be reviewed (if performed), patients will be asked to complete the FACT-Br questionnaire about quality of life, and clinicians will be asked to assess patients using the KPS scale. Data will also be collected for any adverse event occurring outside of clinic visits and any subsequent hospitalizations.

Patient data will be analyzed by tumor type, by the presence of focal or multifocal tumors and by the status of the molecular biomarkers $I D H-1$ and $I D H-2, M G M T$ promoter methylation, $1 \mathrm{p} / 19 \mathrm{q}$ co-deletion and $E G F R$ amplification. Tumor information will include the type and extent of resection, the systems used for surgery (i.e., neuronavigation, photodynamic visualization, or other), initial tumor volume, volume of the residual tumor, and the methods used to capture these data. Concomitant medications will also be recorded.

Survival analysis will be conducted based on biomarker status and on other potential contributing variables (age at diagnosis, gender, KPS at diagnosis, tumor location, early progression, and treatment interventions). Tumor progression will be assessed using the criteria of the Response Assessment in Neuro-Oncology (RANO) working group [58]. In addition, healthcare utilization data will be collected about the length of stay for the primary procedure and the length of stay for any subsequent hospitalization. Safety end points include all serious adverse events, events of interest, and suspected nonserious drug events.

\section{Statistical analysis}

There are two analysis populations in the VIGILANT registry: the full analysis set, consisting of all enrolled patients; and the safety analysis set, consisting of consented patients who undergo a baseline visit and receive 
BCNU wafers. All data summarization and analysis will be performed using Statistical Analysis Software (SAS, NC, USA) version 9.4 or later. The number and percentage of patients who discontinue from the study and the reason for discontinuation and primary cause of death will be summarized. Quantitative variables will be described by the number of observations, mean, standard deviation, and range. Qualitative variables will be described by absolute and relative frequency and number of missing data. All statistical tests will be two sided at the $5 \%$ significance level.

\section{Conclusion}

The 500-patient VIGILANT registry will be one of the largest prospective observational studies ever conducted to track outcomes and practice patterns among patients with CNS malignancies. The rationale for a large-scale analysis of BCNU wafers for treatment of CNS malignancies includes the following considerations: the performance of $\mathrm{BCNU}$ wafers with regard to currently evaluated molecular biomarkers is unknown; data suggesting an increased survival benefit from the combination of BCNU wafers followed sequentially by RT/TMZ is limited to small trials; current practices and outcomes of patients with recurrent HGG might help elucidate best practices; and at a transformative time for neuro-oncology, a large-scale registry might provide needed insights for improving survival and quality of life.

Financial \& competing interests disclosure

The VIGILANT registry is funded by Arbor Pharmaceuticals, LLC. The authors have no other relevant affiliations or financial involvement with any organization or entity with a financial interest in or financial conflict with the subject matter or materials discussed in the manuscript apart from those disclosed.

The authors wish to thank the representatives of Galen Press, Inc., for editorial and administrative support in preparation of this manuscript. Funding support for Galen Press was provided by Arbor Pharmaceuticals.

Trial registration

ClinicalTrials.gov Identifier NCT02684838.

\section{Author contributions}

SN Kalkanis, LM Liau, KO Lillehei, DE Mydland, J Olson, NA Paleologos, and T Ryken are consultants for and provide research support to Arbor Pharmaceuticals. T Johnson and E Scullin are both employees of Arbor Pharmaceuticals.

\section{Open access}

This work is licensed under the Attribution-NonCommercial-NoDerivatives 4.0 Unported License. To view a copy of this license, visit http://creativecommons.org/licenses/by-nc-nd/4.0/

\section{References}

1. Wait SD, Prabhu RS, Burri SH, Atkins TG, Asher AL. Polymeric drug delivery for the treatment of glioblastoma. Neuro Oncol. 17(Suppl. 2), ii9-ii23 (2015).

2. Fleming AB, Saltzman WM. Pharmacokinetics of the carmustine implant. Clin. Pharmacokinet. 41(6), 403-419 (2002).

3. Brem H, Mahaley MS Jr, Vick NA et al. Interstitial chemotherapy with drug polymer implants for the treatment of recurrent gliomas. J. Neurosurg. 74(3), 441-446 (1991).

4. Stewart LA. Chemotherapy in adult high-grade glioma: a systematic review and meta-analysis of individual patient data from 12 randomised trials. Lancet 359(9311), 1011-1018 (2002).

5. Drapeau A, Fortin D. Chemotherapy delivery strategies to the central nervous system: neither optional nor superfluous. Curr. Cancer Drug Targets 15(9), 752-768 (2015).

6. Brem H, Piantadosi S, Burger PC et al. Placebo-controlled trial of safety and efficacy of intraoperative controlled delivery by biodegradable polymers of chemotherapy for recurrent gliomas. The Polymer-brain Tumor Treatment Group. Lancet 345(8956), 1008-1012 (1995).

7. Valtonen S, Timonen U, Toivanen P et al. Interstitial chemotherapy with carmustine-loaded polymers for high-grade gliomas: a randomized double-blind study. Neurosurgery 41(1), 44-48; discussion 48-49 (1997).

8. Westphal M, Hilt DC, Bortey E et al. A Phase 3 trial of local chemotherapy with biodegradable carmustine (BCNU) wafers (Gliadel wafers) in patients with primary malignant glioma. Neuro Oncol. 5(2), 79-88 (2003).

9. Westphal M, Ram Z, Riddle V, Hilt D, Bortey E. Gliadel wafer in initial surgery for malignant glioma: long-term follow-up of a multicenter controlled trial. Acta Neurochir. (Wien) 148(3), 269-275; discussion 275 (2006). 
10. Walker MD, Alexander E Jr, Hunt WE et al. Evaluation of BCNU and/or radiotherapy in the treatment of anaplastic gliomas. A cooperative clinical trial. J. Neurosurg. 49(3), 333-343 (1978).

11. Mutter N, Stupp R. Temozolomide: a milestone in neuro-oncology and beyond? Expert Rev. Anticancer Ther. 6(8), 1187-1204 (2006).

12. Cohen MH, Shen YL, Keegan P, Pazdur R. FDA drug approval summary: bevacizumab (Avastin) as treatment of recurrent glioblastoma multiforme. Oncologist 14(11), 1131-1138 (2009).

13. Stupp R, Mason WP, Van Den Bent MJ et al. Radiotherapy plus concomitant and adjuvant temozolomide for glioblastoma. $N$. Engl. J. Med. 352(10), 987-996 (2005).

14. Stupp R, Hegi ME, Mason WP et al. Effects of radiotherapy with concomitant and adjuvant temozolomide versus radiotherapy alone on survival in glioblastoma in a randomised Phase III study: 5-year analysis of the EORTC-NCIC trial. Lancet Oncol. 10(5), 459-466 (2009).

15. Gilbert MR, Dignam JJ, Armstrong TS et al. A randomized trial of bevacizumab for newly diagnosed glioblastoma. N. Engl. J. Med. 370(8), 699-708 (2014).

16. Gilbert MR, Sulman EP, Mehta MP. Bevacizumab for newly diagnosed glioblastoma. N. Engl. J. Med. 370(21), 2048-2049 (2014).

17. Stupp R, Hegi ME, Gorlia T et al. Cilengitide combined with standard treatment for patients with newly diagnosed glioblastoma with methylated MGMT promoter (CENTRIC EORTC 26071-22072 study): a multicentre, randomised, open-label, Phase 3 trial. Lancet Oncol. 15(10), 1100-1108 (2014).

18. Ashby LS, Smith KA, Stea B. Gliadel wafer implantation combined with standard radiotherapy and concurrent followed by adjuvant temozolomide for treatment of newly diagnosed high-grade glioma: a systematic literature review. World J. Surg. Oncol. 14(1), 225 (2016).

19. Xing WK, Shao C, Qi ZY, Yang C, Wang Z. The role of Gliadel wafers in the treatment of newly diagnosed GBM: a meta-analysis. Drug Des. Devel. Ther. 9, 3341-3348 (2015).

20. Chowdhary SA, Ryken T, Newton HB. Survival outcomes and safety of carmustine wafers in the treatment of high-grade gliomas: a meta-analysis. J. Neurooncol. 122(2), 367-382 (2015).

21. Louis DN, Perry A, Reifenberger G et al. The 2016 World Health Organization classification of tumors of the central nervous system: a summary. Acta Neuropathol. 131(6), 803-820 (2016).

22. Zou P, Xu H, Chen P et al. IDH1/IDH2 mutations define the prognosis and molecular profiles of patients with gliomas: a meta-analysis. PLoS ONE 8(7), e68782 (2013).

23. Hegi ME, Diserens AC, Gorlia T et al. MGMT gene silencing and benefit from temozolomide in glioblastoma. $N$. Engl. J. Med. 352(10), 997-1003 (2005).

24. Gorlia T, Van Den Bent MJ, Hegi ME et al. Nomograms for predicting survival of patients with newly diagnosed glioblastoma: prognostic factor analysis of EORTC and NCIC trial 26981-22981/CE.3. Lancet Oncol. 9(1), 29-38 (2008).

25. Van Den Bent MJ, Weller M, Wen PY, Kros JM, Aldape K, Chang S. A clinical perspective on the 2016 WHO brain tumor classification and routine molecular diagnostics. Neuro Oncol. 19(5), 614-624 (2017).

26. Gorlia T, Delattre JY, Brandes AA et al. New clinical, pathological and molecular prognostic models and calculators in patients with locally diagnosed anaplastic oligodendroglioma or oligoastrocytoma. A prognostic factor analysis of European Organisation for Research and Treatment of Cancer Brain Tumour Group Study 26951. Eur. J. Cancer 49(16), 3477-3485 (2013).

27. Padfield E, Ellis HP, Kurian KM. Current therapeutic advances targeting EGFR and EGFRvIII in glioblastoma. Front. Oncol. 5, 5 (2015).

28. Aoki T, Nishikawa R, Sugiyama K et al. A multicenter Phase I/II study of the BCNU implant (Gliadel((R)) Wafer) for Japanese patients with malignant gliomas. Neurol. Med. Chir. (Tokyo) 54(4), 290-301 (2014).

29. Bock HC, Puchner MJ, Lohmann F et al. First-line treatment of malignant glioma with carmustine implants followed by concomitant radiochemotherapy: a multicenter experience. Neurosurg. Rev. 33(4), 441-449 (2010).

30. Burri SH, Prabhu RS, Sumrall AL et al. BCNU wafer placement with temozolomide (TMZ) in the immediate postoperative period after tumor resection followed by radiation therapy with TMZ in patients with newly diagnosed high grade glioma: final results of a prospective, multi-institutional, Phase II trial. J. Neurooncol. 123(2), 259-266 (2015).

31. Duntze J, Litre CF, Eap C et al. Implanted carmustine wafers followed by concomitant radiochemotherapy to treat newly diagnosed malignant gliomas: prospective, observational, multicenter study on 92 cases. Ann. Surg. Oncol. 20(6), 2065-2072 (2013).

32. McGirt MJ, Than KD, Weingart JD et al. Gliadel (BCNU) wafer plus concomitant temozolomide therapy after primary resection of glioblastoma multiforme. J. Neurosurg. 110(3), 583-588 (2009).

33. Menei $\mathrm{P}$, Metellus $\mathrm{P}$, Parot-Schinkel E et al. Biodegradable carmustine wafers (Gliadel) alone or in combination with chemoradiotherapy: the French experience. Ann. Surg. Oncol. 17(7), 1740-1746 (2010).

34. Miglierini P, Bouchekoua M, Rousseau B, Hieu PD, Malhaire JP, Pradier O. Impact of the peri-operatory application of GLIADEL wafers (BCNU, carmustine) in combination with temozolomide and radiotherapy in patients with glioblastoma multiforme: efficacy and toxicity. Clin. Neurol. Neurosurg. 114(9), 1222-1225 (2012). 
35. Noel G, Schott R, Froelich S et al. Retrospective comparison of chemoradiotherapy followed by adjuvant chemotherapy, with or without prior gliadel implantation (carmustine) after initial surgery in patients with newly diagnosed high-grade gliomas. Int. J. Radiat. Oncol. Biol. Phys. 82(2), 749-755 (2012).

36. Pan E, Mitchell SB, Tsai JS. A retrospective study of the safety of BCNU wafers with concurrent temozolomide and radiotherapy and adjuvant temozolomide for newly diagnosed glioblastoma patients. J. Neurooncol. 88(3), 353-357 (2008).

37. Pavlov V, Page P, Abi-Lahoud G et al. Combining intraoperative carmustine wafers and Stupp regimen in multimodal first-line treatment of primary glioblastomas. Br. J. Neurosurg. 29(4), 524-531 (2015).

38. Salvati M, D'elia A, Frati A, Brogna C, Santoro A, Delfini R. Safety and feasibility of the adjunct of local chemotherapy with biodegradable carmustine (BCNU) wafers to the standard multimodal approach to high grade gliomas at first diagnosis. J. Neurosurg. Sci. 55(1), 1-6 (2011).

39. US Department of Health. Common Terminology Criteria for Adverse Events (CTCAE). Version 4.0. Washington DC: National Institutes of Health (2010). https://evs.nci.nih.gov/ftp1/CTCAE/CTCAE_4.03_2010-06-14_QuickReference_8.5x11.pdf

40. Hottinger AF, Pacheco P, Stupp R. Tumor treating fields: a novel treatment modality and its use in brain tumors. Neuro Oncol. 18(10), 1338-1349 (2016).

41. Inda MM, Bonavia R, Mukasa A et al. Tumor heterogeneity is an active process maintained by a mutant EGFR-induced cytokine circuit in glioblastoma. Genes Dev. 24(16), 1731-1745 (2010).

42. Arimappamagan A, Kruthika, Dawn R, Paturu K, Santosh V. 332 molecular characteristics of tumor infiltrating front in glioblastoma: insights into molecular heterogeneity and implications on targeted therapy. Neurosurgery 63(Suppl. 1), 197 (2016).

43. Qazi MA, Vora P, Venugopal C et al. Intratumoral heterogeneity: pathways to treatment resistance and relapse in human glioblastoma. Ann. Oncol. 28(7), 1448-1456 (2017).

44. Weller M, Cloughesy T, Perry JR, Wick W. Standards of care for treatment of recurrent glioblastoma - are we there yet? Neuro Oncol. 15(1), 4-27 (2013).

45. Ryken TC, Kalkanis SN, Buatti JM, Olson JJ. The role of cytoreductive surgery in the management of progressive glioblastoma: a systematic review and evidence-based clinical practice guideline. J. Neurooncol. 118(3), 479-488 (2014).

46. Klein J, Juratli TA, Radev Y et al. Safety and effectiveness of bis-chloroethylnitrosourea wafer chemotherapy in elderly patients with recurrent glioblastoma. Oncology 93(1), 43-50 (2017).

47. Anderson FA Jr. Glioma Outcomes Project Advisory B. The Glioma Outcomes Project: a resource for measuring and improving glioma outcomes. Neurosurg. Focus 4(6), e8 (1998).

48. Chang SM, Parney IF, Mcdermott M et al. Perioperative complications and neurological outcomes of first and second craniotomies among patients enrolled in the Glioma Outcomes Project. J. Neurosurg. 98(6), 1175-1181 (2003).

49. Laws ER, Parney IF, Huang W et al. Survival following surgery and prognostic factors for recently diagnosed malignant glioma: data from the Glioma Outcomes Project. J. Neurosurg. 99(3), 467-473 (2003).

50. Litofsky NS, Farace E, Anderson F Jr et al. Depression in patients with high-grade glioma: results of the Glioma Outcomes Project. Neurosurgery 54(2), 358-366; discussion 366-357 (2004).

51. Chang SM, Parney IF, Huang W et al. Patterns of care for adults with newly diagnosed malignant glioma. JAMA 293(5), 557-564 (2005).

52. Chang SM, Barker FG 2nd, Schmidt MH et al. Clinical trial participation among patients enrolled in the Glioma Outcomes Project. Cancer 94(10), 2681-2687 (2002).

53. Olson JJ, Nayak L, Ormond DR et al. The role of targeted therapies in the management of progressive glioblastoma: a systematic review and evidence-based clinical practice guideline. J. Neurooncol. 118(3), 557-599 (2014).

54. Ulmer S, Spalek K, Nabavi A et al. Temporal changes in magnetic resonance imaging characteristics of Gliadel wafers and of the adjacent brain parenchyma. Neuro Oncol. 14(4), 482-490 (2012).

55. Colen RR, Zinn PO, Hazany $S$ et al. Magnetic resonance imaging appearance and changes on intracavitary Gliadel wafer placement: a pilot study. World J. Radiol. 3(11), 266-272 (2011).

56. Peters KB, West MJ, Hornsby WE et al. Impact of health-related quality of life and fatigue on survival of recurrent high-grade glioma patients. J. Neurooncol. 120(3), 499-506 (2014).

57. Schag CC, Heinrich RL, Ganz PA. Karnofsky performance status revisited: reliability, validity and guidelines. J. Clin. Oncol. 2(3), 187-193 (1984).

58. Wen PY, Macdonald DR, Reardon DA et al. Updated response assessment criteria for high-grade gliomas: response assessment in neuro-oncology working group. J. Clin. Oncol. 28(11), 1963-1972 (2010). 
